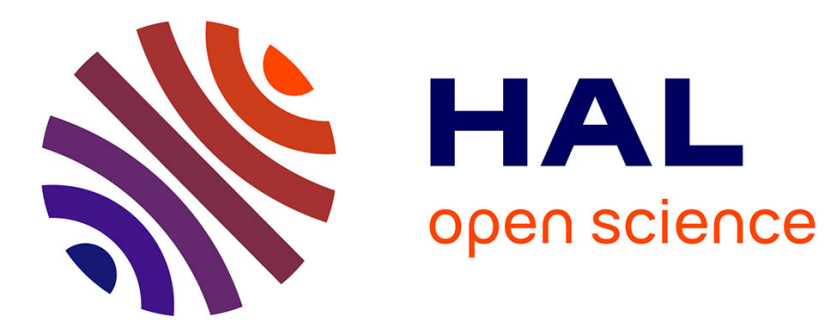

\title{
Dietary models and challenges for economics
}

Stéphan Marette, Vincent Réquillart

\section{To cite this version:}

Stéphan Marette, Vincent Réquillart. Dietary models and challenges for economics. Review of Agricultural, Food and Environmental Studies, 2020, 101 (1), pp.5-22. 10.1007/s41130-020-00113-z . hal-03124338

\section{HAL Id: hal-03124338 \\ https://hal.inrae.fr/hal-03124338}

Submitted on 19 Jul 2021

HAL is a multi-disciplinary open access archive for the deposit and dissemination of scientific research documents, whether they are published or not. The documents may come from teaching and research institutions in France or abroad, or from public or private research centers.
L'archive ouverte pluridisciplinaire HAL, est destinée au dépôt et à la diffusion de documents scientifiques de niveau recherche, publiés ou non, émanant des établissements d'enseignement et de recherche français ou étrangers, des laboratoires publics ou privés.

\section{다)(1) $(5$}

Distributed under a Creative Commons Attribution - NonCommerciall 4.0 International 


\title{
Dietary models and challenges for economics
}

\section{Stéphan Marette ${ }^{1}\left[\right.$ [ $\cdot$ Vincent Réquillart $^{2}$}

Received: 29 October 2019 / Accepted: 13 June 2020 / Published online: 16 July 2020

(C) INRAE and Springer-Verlag France SAS, part of Springer Nature 2020

\begin{abstract}
This introductory article presents the three main challenges faced in economics to issues raised by dietary models. The first part of this paper examines the dietary models that maximise the health profile of a population under various constraints, including environmental and agronomic criteria. The second part introduces the possibilities of economic modelling to complement these dietary models, despite the limitations of economic approaches. The third part suggests new research proposals by asserting that overlooked questions deserve further scrutiny. We emphasise that economic models are particularly useful to analyse trade-offs between the various objectives underlying a sustainable food system. However, possible improvements should tackle, first, possible substitutions between food categories by consumers; second, adjustments in supply chains; and third, measures of inequality resulting from significant changes towards sustainability. Such improvements may be difficult to realise but are technically possible.
\end{abstract}

Keywords Dietary models · Unbalanced diet · Food production system · Sustainability

\section{Introduction}

In many countries, an unbalanced diet is responsible for obesity, diabetes and cardiovascular diseases, entailing major costs for society (WHO 2015). While around 650 million people in the world are classed as obese, around 820 million people in the world remain hungry (FAO 2019). Moreover, the food production system involves a number of pollutants related to pesticide application, the use of plastics and packaging from the farm to the refrigerator, the presence of residual ammoniac or nitrates that spread through soil and water, and greenhouse gas (GHG) emissions within the food chain, which represent $21 \%$ to $37 \%$ of emissions throughout the world (IPCC 2019).

Stéphan Marette

marette@agroparistech.fr

1 Université Paris-Saclay, INRAE, AgroParisTech, UMR Economie Publique, Avenue Lucien Bretignières, 78850 Grignon, France

2 Toulouse School of Economics, INRAE, University of Toulouse Capitole, Toulouse, France 
These pollutants also impact human health and biodiversity (Lock et al. 2010). All of these issues underscore the immense challenges that need to be overcome in achieving a sustainable food system, guaranteeing the availability of food for everybody with sound nutritional and environmental qualities, all of which encompass a wide range of characteristics (Ranganathan et al. 2016).

This situation has generated numerous public agendas for sustainable development, clean agriculture, and/or a zero-hunger target by 2040 or 2050 . These agendas are based on foresight studies with legitimate objectives, but they are often also based on debatable assumptions regarding economic development (FAO 2019). In this context, the scientific knowledge regarding diets appears to be a keystone in predicting the future of food security, which has led to the emergence of many dietary models (Poore and Nemecek 2018). Several works studying diets have highlighted the substantial benefits that could arise from significant, but still hypothetical, changes in diet (Lock et al. 2010). ${ }^{1}$ For example, according to Vieux et al. (2018), adopting diets that are healthy and that reduce GHG emissions by $30 \%$ would require more than $50 \%$ of our current food intake to be replaced by other food products. This study, along with many others (such as Tilman and Clark 2014), is based on dietary models in which price and market adjustments are completely overlooked.

Dietary models provide insights on 'desirable' targets regarding numerous characteristics related to nutrition and environment, but remain silent on the economic conditions that should (broadly) prevail to have any chance of reaching them. For example, food habits make dietary changes difficult and generally slow in uptake. Moreover, consumers cannot take into account all of the criteria and trade-offs linked to sustainability, which limits their ability to influence the market in providing incentives towards sustainable foods (Lusk 2014). Additionally, supply chains are not always organised to promote new and sustainable practices. Regulation is certainly necessary, but the numerous dimensions related to sustainability make this regulation extremely difficult and potentially set up to fail (Roosen and Marette 2011).

Even if reaching sustainability remains challenging, we argue that economic analysis can contribute to the key issues underpinning dietary models by providing information on consumers' behaviour, price adjustments and regulation. Although economic models are imperfect, these models are useful for understanding the impacts of regulatory tools on market adjustments and agents' surpluses, taking into account agents' behaviours.

As changes suggested by dietary models are ambitious (Afshin et al. 2019), economic models are important for quantifying the various losses and gains involved and for guiding the regulatory debates that should combine efficiency and social considerations in making dietary reforms acceptable. If economic analyses are sufficiently precise, they can contribute to our understanding of who the winners and losers coming from drastic changes could be, and how to move towards a sustainable transition in the food production system. In other words, foresight studies based on dietary models need

\footnotetext{
${ }^{1}$ Modifying diets is not the only way to make food systems more sustainable. The supply side can also contribute to better health thanks to product reformulation, for example, or by lowering GHG emissions due to changes in production methods. However, following Poore and Nemecek (2018), dietary changes are requested to include more sustainable food systems in the future.
} 
to be more accurate regarding market adjustments and economic gains in providing political credibility that lead to real change.

In introducing this special issue on the Economics and Sociology of the FoodHealth-Environment Nexus, this article aims to underline the main challenges addressed by dietary models in economics. Specifically, this article focuses on these important scientific contributions and their consequences for economics, since the Food-Health-Environment Nexus raises many social questions. We mainly restrict our analysis to health and environmental criteria, knowing that criteria such as fair trade, inclusive development and rural/urban equilibrium also matter. We also abstract from the important issues specifically related to developing countries, such as poverty, starvation or the fragility of small-scale farmers (NBER 2019). We also voluntary restrict our attention to the specific field of economics; however, the reader should remain aware that these challenges also question other social sciences, such as sociology, anthropology and/or political sciences.

The first part of this brief article presents the essence of dietary models by summarising a few recent contributions. The second part introduces the possible contributions of economic modelling to complement these dietary models, despite the limits of economic approaches. The third part suggests new research proposals by underlining overlooked questions that deserve further scrutiny.

It should be noted that we have not written a survey covering an exhaustive review of previous contributions. Indeed, this introductory article to the Economics and Sociology of the Food-Health-Environment Nexus is rather a presentation of arguments arising from the recent literature and a chance to highlight research priorities to tackle unanswered questions. We now turn to a brief presentation of dietary models.

\section{Dietary models}

Analyses developed by nutritionists and agronomists evaluate the impact of dietary recommendations with dietary models using constraints that embrace nutrition/health, agronomic and environmental dimensions (see Vieux et al. 2012). These models estimate per-person intakes for different groups of citizens and link these food intakes to first, agronomic and environmental models for estimating the impact of diets on land use, GHG emissions or other environmental criteria, and/or second, epidemiological models for measuring the impact of diets on human health. The dietary models provide a number of precisions regarding food products, as there are frequently more than 100 different food products involved. These models also measure the potential changes in consumption that could arise from possible recommendations to improve sustainability.

Diets strongly impact health. The World Health Organization (WHO) considers that unbalanced dietary factors-along with unsafe sex, smoking and alcohol consumption-are the main modifiable risk factors (WHO 2009). The diet-related risks depend on the level of development within a country; however, it is important to note that whatever the country, diet is always high on the list of top modifiable risk factors. According to Afshin et al. (2019), in 2017, 11 million deaths (22\% of all deaths among adults) and 255 million disability-adjusted life-years (DALYs) (15\% of all DALYs among adults) in the world were attributable to dietary risk factors, which highlight the need to improve diets across nations. They also point out that "although sodium, sugar and fat have been the main focus of diet 
policy debate ... our assessment shows that the leading dietary risk factors for mortality are diets high in sodium, low in whole grains, low in fruits, low in nuts and seeds, low in vegetables, and low in omega-3 fatty acids." (pp 1967). Some of their results could be challenged (e.g. the magnitude of the health impact of a low intake of whole grains (see Jones et al. 2019); however, the global view that diets that are much more plant based are healthier is a view shared by many authors.

In facing the burden of diseases and the necessity of improving diets, several papers have attempted to estimate the impact of alternative diets compared to actual diets. They also integrate additional dimensions into their analyses. For example, Tilman and Clark (2014) underline the strong empirical evidence for the effect of diet on both health and the environment. They find that the actual average diet has a strong incidence of noncommunicable diseases, such as type II diabetes and coronary heart disease, and are (and will continue to be) a major contributor to agricultural GHG emissions. In particular, they estimate the impact of various shifts in diets. Indeed, they measure the influence of shifts towards Mediterranean, pescatarian or vegetarian diets. Their analysis suggests that alternative diets that are richer in fruits, vegetables and pulses could both reduce these environmental effects and offer substantial health benefits.

Many other approaches confirm these results. For instance, Masset et al. (2014) define optimal diets by considering various constraints, taking into account "LowerCarbon," "Higher-Quality," "More Sustainable" diets or diet costs. Whitmee et al. (2015) define ambitious sustainable diets for different regions of the world. They review many scientific results coming from ecology, agronomy, food science, nutrition and health (see also IPCC 2019). These various contributions suggest that an improved diet would likely result in strong health benefits for citizens. These previous papers recommend: first, a decrease in the consumption of meat, sugar products and processed industrial dishes; and second, an increase in the consumption of fruit and vegetables, seeds and nuts, whole grains and legumes (peas, beans, lentils, etc.). They also state that beyond a significant reduction in chronic diseases, these dietary changes would have a significant impact on both the environment and household expenditure. Proposed changes in dietary composition are supported by a mix of health and environmental considerations (Vieux et al. 2018). ${ }^{2}$ For example, if an increase in the consumption of fruit and vegetables is primarily driven by health considerations, the decrease in meat consumption is primarily driven by environmental considerations.

Depending on the studies, the implicit weight given to the different objectives (improving health, reducing GHG emissions, reducing land-use, ...) varies. For example, in addition to reduce the over-consumption of calories, Ranganathan et al. (2016) focus on limiting the over-consumption of protein (mostly in high-income countries) by reducing the consumption of animal-based proteins. Some other approaches attempt to develop a broad view of the link between nutrition and land use. The foresight study developed by the Agrimonde-Terra consortium examines the link between land use and food security looking ahead to 2050 at the world level, by integrating various measures of climate change, diets, urban-rural

\footnotetext{
${ }^{2}$ In Vieux et al. (2018), consumers are supposed to choose a new diet that minimizes a distance function between the observed diet and the optimized one (the so-called 'optimized diets'). To make solutions acceptable, ad-hoc constraints (denominated 'palatability constraints') are frequently added to nutritional constraints or environmental constraints (e.g., a limit in GHG emissions). This differs from Tilman and Clark (2014) and Whitmee et al. (2015), where exogenous new diets, based for example on nutritional goals, are assumed and the consequences evaluated.
} 
linkages, farm structures, cropping and livestock systems (Agrimonde-Terra 2018). This last contribution underlines the fragility of efficient land use compatible with both a sustainable diet and development, including a decent income for small-scale farmers in developing countries. In particular, Agrimonde-Terra estimates the impact of a reduction in the consumption of animal proteins in developed regions, combined with the development of agroecological methods of production that lead to better nutrition and less deforestation, compared to the present situation.

More generally, land use has a pivotal role in many agronomic adjustments. For instance, if decided on a large scale (namely, organic goods being more than $50 \%$ commodities), organic farming may have a bigger climate impact than conventional farming (or at least it does not allow an improvement in the carbon footprint of farming), because greater areas of arable land are required to outweigh the yield reduction linked to organic farming (Searchinger et al. 2018). This ultimately raises questions related to possible trade-offs in order to choose between different objectives, such as biodiversity preservation, lowering health risks or mitigating climate change.

Recently, the EAT-Lancet Commission (Willett et al. 2019, p.1) proposed a "universal healthy reference diet to provide a basis for estimating the health and environmental effects of adopting an alternative diet to standard current diets". This alternative healthy reference diet was created using the idea of 'safe operating systems', that is, a set of constraints that need to be satisfied in order to achieve better human health and environmental sustainability. A key result from this work is that adopting such a diet requires a significant modification of our current diets. The interested reader should refer to the first figure of this paper (pp. 14) that shows the gap between current diets and the alternative healthy reference diet for 11 food groups. Roughly, in most regions, the reference diet requires a significant increase in the consumption of fruit, whole grains, legumes, vegetables and nuts, and to significantly decrease the consumption of red meat and starchy vegetables. Willett et al. (2019) underline that this reference diet is compatible with a projected sustainable food system that could nourish 10 billion people in 2050. It should be noted that this new food system is interlocked with the effective reduction of both obesity and undernutrition problems around the world. In other words, these key improvements concern all rich and poor countries together.

These previous dietary models are used to define diets that (could) improve the healthiness of dietary intake and limit GHG emissions (and other pollutants). They suggest that improving both the population's level of healthiness and the environmental sustainability of diets is theoretically possible. These models focus on variations in dietary intake in order to satisfy objectives, but without detailing precisely how to move in this sustainable direction and without describing policies, which is a major flaw. As changes suggested by dietary models are generally considered to be ambitious, the economic models are important for quantifying the various losses and gains and for guiding regulatory debates that should combine efficiency and social considerations for making diet reforms acceptable. For instance, in the scenario defined by Willett et al. (Willett et al. 2019), the intake of red meat should decrease by $50 \%$ or more in many areas of the world, representing a "sustainable intake" ( $-77 \%$ for Europe), which means that the social impact on retailer, processors, farmers, feeding and grasslands would be vast. ${ }^{3}$

\footnotetext{
${ }^{3}$ These recommended reductions are much greater than the small ones observed in many Western countries over the past decade. For example, in France, per-inhabitant meat consumption fell by $11 \%$ between 2007 and 2017 (Tavoularis and Sauvage 2018).
} 
Indeed, the different dietary models, including Vieux et al. (2012), Tilman and Clark (2014) and Agrimonde-Terra ( 2018), do not directly integrate consumers' behaviours, which is a major shortcoming. They do not provide any details on the impact of price adjustments on food consumption, and there is no guarantee that targeted diets are compatible with actual and future consumers' preferences and market incentives. Moreover, by ignoring economic mechanisms, they cannot be used to design policies and regulations needed in order to reach targeted and wishful diets. They also overlook a deep analysis regarding the effects of regulatory tools on dietary changes.

Regarding their potential usefulness for defining consistent public policies, an important limitation of these models consists of overlooking the weight given to different criteria (improving health, reducing GHG emissions, etc.). Thus, dietary models do not provide much information to be able to evaluate the trade-off between different objectives. In other words, dietary models do not provide many clues as to what society should improve as a particular priority (in terms of the healthiness of various diets) in order to reduce the strain of optimised diets on land use and pollution, such as GHG emissions or soil/water deterioration. The question of arbitrages between different objectives ultimately refers to the sovereignty of citizens being able to prioritise from amongst the numerous criteria that define sustainability. Obviously, this sovereignty depends on the citizens' ability to master and harness the related scientific knowledge. Some replies can be provided by social sciences, including economics, sociology, political science and science-society dialogue.

To conclude, these models are very useful in order to define the targets but provide no help in determining how to reach them, or in defining the key priorities from amongst the different objectives. The following sections address all of the overlooked questions related to incentives and price adjustments in the food system.

\section{Contributions and limits of economic analyses}

Economic analysis can contribute to questions underlined by dietary models by providing elements related to price adjustments, agents' incentives and regulation. In other words, while dietary models focus only on quantity adjustments, economic analysis considers both quantity and price adjustments and their consequences for the different agents. Without being exhaustive, this section simply covers three main topics, namely the understanding of consumers' behaviour, the quantification of market adjustments and the impact on welfare. These three topics are now presented, in addition to which, we also discuss their main limitations, which are not directly tailored to the objectives raised by the dietary models presented in the previous section.

\section{Integrating consumers' behaviour in the analysis of the impact of policies}

Dietary models do not generally consider consumers' behaviour and are not based on a theory of consumption. Consumers' behaviours depend on many criteria. Thus, the drivers of food demands include price, income, tastes, quality, consumption habits, health concerns, the availability of ready-made foods, plus various perceptions 
influenced by advertising, newspapers and educational policies. ${ }^{4}$ Regarding sustainability, perceptions are particularly important but difficult to influence. For instance, from a survey conducted with 788 French participants, Brunelle et al. (2017) show that consumers are relatively reluctant to turn their dietary habits towards more sustainable foods, indicating other priorities regarding sustainability and the reduction of GHG emissions in areas such as housing or equipment (see also Krystallis et al. 2012). Such a result means that an ambitious and sustainable food system may receive little attention from consumers and little political support for the implementation of more stringent policies.

This absence of a "concrete" willingness to change behaviours is particularly explicit when we observe meat consumption in many Western countries. Entrenched habits, beliefs and purchasing routines favouring meat consumption in regular diets often thwart consumers' abilities to reduce meat consumption (Kemper 2020). Indeed, cultural and social factors explain the overconsumption of animal-based proteins in many developed countries (Milford et al. 2019). ${ }^{5}$ Hartmann and Siegrist (2017) underline that consumer awareness of the environmental impact of meat production is generally very low across Western countries. This fact raises the issue of efficiently transmitting complex environmental knowledge about cattle breeding and methane emissions, contamination of soil and water by ammoniac, nitrate or antibiotic residues and various impacts on grasslands. Harguess et al. (2020) emphasise that increasing knowledge about health, environmental and animal welfare aspects may persuade some consumers to slightly reduce their meat consumption. Indeed, scientific knowledge of the consequences of meat consumption is very complex. Even more, the direct economic consequences of conventional diets can be underestimated by consumers. For example, based on the average weekly expenditure of a French family, a "diet" study published by WWF shows that switching from a "current basket" to a "flexitarian basket" would lead to a $21 \%$ drop in the monetary cost of this basket, mainly via the reduction in meat consumption (WWF 2018). Such a figure may be interpreted by a lack of awareness about potential savings coming from alternative diets, but also by strong and "resistant" preferences for meat.

However, economic models encounter difficulties in integrating consumers' health/ environmental concerns, since expectations regarding the health/environmental impacts of food choices are not explicitly integrated into the structural models. For example, when evaluating the impact of a policy on health, in most models, the policy is supposed to impact food consumption, which in turn impacts consumer health. However, the feedback loop (that is, a change in health affects' consumption in return), is often ignored. In the case of health, the feedback loop mainly depends on the own choice of a consumer. For example, Lakdawalla et al. (2005) developed a model in which the utility not only depended on food consumption but also on weight. In that case, a change in body weight, interpreted as a health indicator, affects consumption. In the case of environment, this could also be the case but the feedback loop depends on the choices of all consumers. This is the first limit in the existing studies, in which the impact on the demand of policies is based on utility functions that do not take into

\footnotetext{
${ }^{4}$ In developing countries, many farmers face the food prices as both producers and consumers.

${ }^{5}$ By considering many countries, Sans and Combris (2015) underscore the positive link between the income per inhabitant and the meat consumption per inhabitant.
} 
account potential feedbacks. As a consequence, the estimated impact on consumer surplus is biased (Meunier 2019). In addition, we know that consumer choices are impacted by numerous behavioural biases, such as the tolerance of risk, conformity to social norms, impulsivity and loss aversion. For instance, some consumers may voluntarily disregard the recommendations for a significant reduction in meat consumption as advised by many dietary models. The understanding of consumers' beliefs and more generally of consumers' behaviours requires collaboration with both sociologists and psychologists.

A standard method of analysis consists of building up models that focus on the "present" demand side of the market and to study the impact of different policies on food choices. These models, when linked with epidemiological models and/or environmental models, help to evaluate whether or not the simulated policies act in the "desirable" direction (see Irz et al. 2015). They allow for the measurement of consumers' losses and gains coming from a policy with a monetary value related to the variation of the indirect utility. They are also useful in discussing whether or not health and environmental goals are compatible (for an in-depth discussion, see Doro and Réquillart in this special issue of the journal). However, they too suffer from important limitations: unlike dietary models, which frequently consider a large number of food products allowing substitutions between and within food products categories, economic models frequently consider a limited number of products. In most cases, they focus on substitutions between food product categories. This type of substitution, when occurring, is likely to have a significant impact on health and the environment; however, because such substitutions imply significant changes in the diet, consumers may be reluctant to adopt these changes, as revealed by the inelasticity of demand when evaluated at the food product category level. Only a few models focus on a specific group of products (e.g. animal products, as in Bonnet et al. 2018) to evaluate substitutions within product categories. From the consumer's point of view, substitutions within a food product category are easier, but may have a smaller impact on health and the environment. Indeed, because demand models integrate a limited number of products, they fail to simultaneously consider substitutions between and within food product categories. For example, in the case of meat products, which represent a significant part of the food budget, models that consider the whole diet integrate only three or four different meat products, whereas the model developed by Bonnet et al. (2018) consider more than 20 products, allowing for much more precise analysis.

The models that rely on the estimates of demand systems are able to characterise consumers' losses and gains for relatively low variations of product prices or consumption changes. In other words, as direct and indirect price elasticities of demand that epitomise consumers' preferences are estimated with relatively small variations of price, the larger changes suggested by dietary models cannot be satisfactorily measured with consumers' surpluses, because consumers' preferences are known but only on restricted intervals related to observed consumption patterns. These changes are so important that the consumers' preferences are a terra incognita, impeding a monetary measure by consumption models. Estimating the welfare impact coming from a drastic reduction in the intake of red meat greater than 50\%, as suggested in the previous section, is almost impossible, since the estimates of changes in the Hicksian/ Marshallian surplus appear accurate and credible for relatively small variations of prices/quantities. 
Beyond these limits, the models focusing on consumers' behaviours abstract from the markets' adjustments with a supply side. These market adjustments are now presented.

\section{Market adjustments and equilibrium models}

Market modelling can be divided in multi-market approaches accounting for substitutions between the whole set of food product categories and partial equilibrium models that focus on market adjustments for a subset of products, which are frequently involved in a single product category.

The multi-market approaches seek to understand how changes and/or policies may affect production across different categories of foods (meat, fruit and vegetables, etc.). They encompass general computable equilibrium models, such as GTAP (see GTAP 2019) and those involving a combination of partial-equilibrium models for different categories of products (such as Fapri 2019 or Globiom 2019). These models mainly focus on agricultural production with some additional links to land use or GHG emissions. ${ }^{6}$ Because they are mainly used to analyse the impact of agricultural or environmental policies, the demand for final food products is oversimplified. In particular, the link between the demand for processed food products, which now represents most food products, and the supply of agricultural raw products is generally poorly modelled. As a consequence, these models are not designed to evaluate the impact of policies on health.

A notable exception comes from Springmann et al. (2017), who develop a simplified supply/demand model coupled with impacts on health, in order to consider how the supply chain would react to changes in consumption. In this paper, they use an agriculture-economic model to project future food consumption for 62 agricultural commodities in over 150 world regions. Their analysis accounts for "price-mediated changes" in the consumption of particular commodities, as well as the effects of price changes on substitutions across food groups. Using a coupled agriculture and health modelling framework, Springmann et al. (2017) show that the global climate change mitigation potential of the emission pricing of food commodities could be substantial. Additionally, imposing GHG taxes on food commodities could, if appropriately designed, be a health-promoting climate policy in high-income countries, as well as in most low- and middle-income countries. ${ }^{7}$ However, in this important paper, supply chain adjustments with processors and retailers are overlooked, consumers' demands are not detailed and possible shifts in the quality of products are overlooked.

Given the important changes in diets that are suggested by dietary models, it is useful to analyse more precisely how the entire food chain can adapt. Partialequilibrium models focusing on market adjustments for a single product category could also be useful (see, for instance, Marette et al. (2008) for market adjustments in the case of fish markets). These models allow the precise consideration of the qualities of products and their impact on equilibrium prices. Thus, producers in a supply chain

\footnotetext{
${ }^{6}$ It should be noted that originally, many models in agricultural economics were not designed for complementing dietary models but rather to analyse the impact of agricultural and/or environmental policies. ${ }^{7}$ Note that GHG taxes on all food products have a negative health impact (Springmann et al. 2017). However, a scenario that combines GHG taxes on most polluting products (animal products) and subsidies on fruit and vegetables leads to a health improvement.
} 
can modify the characteristics of their products. They can modify an existing product, but perhaps, more importantly, the supplier can develop new products. In such a context, regulations are likely to spark significant quality improvements. For instance, if taxes on meat drastically increase, complex and significant substitutions will happen at both production and consumption levels.

Beyond the specificities of models that study market adjustments, the Achilles Heel of many models are the market adjustments along the supply chain, involving many agents, from farmers to retailers. Structural econometric models allow us to distinguish between farmers' or processors' and retailers' margins, which is promising for understanding vertical relationships. For example, Bonnet and Bouamra-Mechemache (2016) computed both retailers' and manufacturers' margins for regular and organic milk in France, and showed that per-unit margins in the organic sector are higher than those in the conventional sector. These methods are promising for evaluating profit sharing in the supply chain.

However, regarding the supply chain, there is a lack of analysis studying the functioning and adjustments of supply chains. Eliciting these adjustments in the supply chain is crucial for understanding the losses/benefits implied by large changes in demand. In particular, the existence of sunk (that is, non-recoverable) costs may lead to bankruptcies in sectors that experiment a dramatic drop in sales, a mechanism that could be underestimated by policy makers.

Being precise on possible adjustments in different supply chains is very difficult to realise when many products are taken into account, as is the case with multi-market approaches. The task is particularly challenging for evaluating regulatory decisions that impact the organization of supply chains and the contracts between farmers, processors and retailers. We now briefly discuss the possible regulations and their limits.

\section{Welfare measures for evaluating policies}

Regulation is crucial for reaching sustainable production. However, there is no certainty that regulation improves agents' situations, because of costs and distortions arising from regulatory instruments. There are three types of instruments influencing markets' functioning: first, the minimum quality standard imposing some mandatory production norms, thus targeting the supply side of the market; second, the recommendations, warnings and labels informing consumers, thus targeting the demand side of the market; and third, the mechanisms of taxes and subsidies depending on products quality and impacting prices. Regarding the optimal policy, there is no clear theoretical conclusion about the optimal instrument to select; then, economists advise in order to minimise market distortions coming from regulations (see Disdier and Marette 2012).

In this context, defining precise measures of preferences and welfare is often essential in order to judge or define efficient policies. Even if biotechnical disciplines were able to quantify all of the relationships between agriculture, food, health and the environment, it would be very difficult for a regulator to define a socially optimal policy with clear priorities and maximised surpluses for agents. Multiple causalities make the food system extremely problematic to decipher, given the large number of sectors and producers, along with the vast heterogeneity of diets. Dietary models, as presented in the previous section, can be broadly characterised as multi-criteria analyses, insofar as they provide the consequences on the different dimensions of modifying 
diets. However, a key question for policy makers is how to define "optimal" policies when their likely impacts are positive for some criteria (e.g. to improve health) and negative for others (e.g. to increase GHG emissions). Establishing a map of consumers and/or citizen preferences regarding environmental and health criteria is a task of monumental proportions. With multi-criteria analyses, the weightings between the different criteria remain delicate and not always transparent. The economic studies via welfare indicators and cost-benefit analyses (CBA) allow us to find a common metric via a monetarization of products or policies that influence the vast pool of health and environmental criteria. These methods represent a practical way of clarifying tradeoffs among various criteria and objectives defining a sustainable food system, and should help in defining priorities.

Many CBAs integrate econometric methods, methods of valuation of environmental/ health goods (via contingent valuation or choice experiment) and/or methods of experimental economics to produce monetarised evaluations of public policies. For example, the results of experiments in the laboratory or in specific fields with "randomised" approaches make it possible to identify changes in consumption behaviour following the dissemination of information concerning a food product or a set of products. These methods of experimental economics allow us, in particular, to measure the Willingness to Pay (WTP) by consumers for little known or observable characteristics that are subject to public regulations (see Lusk and Shogren 2007). Estimating this WTP is particularly important for studying new possibilities regarding the Pigouvian taxation of food. For instance, Springmann et al. (2018) estimate high levels of per-unit taxes on meat for internalizing health-related costs incurred by citizens and society, measured by the so-called value of statistical life, coming from WTP for a reduction in the risk of mortality. Moreover, experimental methods may help to determine a hierarchy of preferences among the multiplicity of criteria. For foods of similar value, the premium (or marginal WTP) for a characteristic impacting human health is higher than the premium impacting the environment (Roosen and Marette 2011).

However, these methods relying on experimental economics remain fragile in terms of guiding policy making, since estimation biases have been often underlined (Thaler 2015). WTP as a characteristic may vary depending on whether it is evaluated on its own or as part of a "broad basket" of goods/characteristics. In particular, Kahneman and Knetsch (1992) underlined the sub-additivity effect that occurs when the estimated WTP for the improvement of one characteristic plus the estimated WTP for another characteristic is greater than the "common WTP", when participants are asked to value the two characteristics together. This raises the issue of estimating credible WTP when many nutritional and environmental characteristics may be influenced by a food policy.

All of the limits underscored in this section underscore the fragilities of economic estimations, and they should be taken into account in future analyses. We now turn to new possibilities of research.

\section{New research proposals}

The first possibility could involve integrating the adjustments advised by dietary models into the existing models in order to measure potential economic effects. For instance, it may be possible to examine dietary shifts suggested by dietary models via 
partial equilibrium adjustments, accounting for consumers and supply chains. If intakes for one type of food decrease by $\mathrm{x} \%$, as suggested by dietary models, a partialequilibrium model could be useful for complementing the analysis and determining, first, what the best tool(s) for reaching such a variation will be, and second, what the losses/gains for producers and consumers will be. These works could be developed in the future to bridge the gap between dietary models and economic models when studying sustainable food systems. However, such a possibility is greatly disadvantaged by the extent of shocks and the difficulty of existing economic models to account for large shocks, as explained above.

The limitations of the economic models underlined above should be seriously taken into account, leading to major improvements. To open the debate further, we now provide some suggestions for improvements, being aware that the challenges of being precise regarding the market adjustments are enormous. Improvements concern both demand and supply sides, which we now detail.

\section{Improvements regarding the demand side of models}

(a) A first direction could consist of extrapolating the demand system and the related elasticities of "active outliers", as young people or the flexitarian/vegetarian. Young consumers' food habits and the analysis of the evolution of food habits based of different cohorts could be used to determine a projection of future possibilities of consumption for a whole population, but prospective studies cannot lead to an estimation of a complete demand system (Blezat et al. 2017). Food habits of flexitarian or vegetarian consumers could also be used to understand how the system could evolve when the demand for meat may plummet on a large scale. These "clues" are still nascent ideas that deserve further study;

(b) Dealing with more food products could be an interesting option when systems of food demand are estimated. Typically, economic models integrate 20 to 30 products, while dietary models account for more than 100 to 200 food categories. Increasing the number of food products considered (towards 60 or 70) would greatly improve the link with health models and/or environmental and/or agronomic models. This would allow taking into account both substitutions between food product categories and substitutions within product categories, despite the difficulties of estimating a high number of cross-price elasticities, which may be bypassed by methodologies, such as the multi-stage budgeting (Deaton and Muellbauer 1980). Taxes and subsidies could be computed by reaching low or medium variations in consumption, compatible with the direction indicated by several dietary models for the different food categories;

(c) Regarding the number of products, the level of aggregation should depend on regulatory questions by disaggregating some product categories directly concerned with the regulation, while keeping some other sectors much less disaggregated. For instance, for questions related to a reduction of meat consumption, it may be possible to focus on different types of meats in the context of a whole demand system considering other sectors as much more aggregated. This could allow taking into account the quality issues or specific links with supply systems (namely, meat from dairy cows versus meat from ox), or different meat production systems with more or less grassland for feeding animals; 
(d) In most cases, consumers' demands only relate to at-home consumption. Nowadays, food consumption out-of-home represents about $25 \%$ of food expenditure in France (and even more in some countries such as the U.S.). School cafeterias and restaurants are an important source of innovation regarding new trends and alternative food habits. Economists should devote more efforts towards analysing these demands in cafeterias and restaurants, and more broadly to out-of-home consumption.

All of these improvements regarding the demand sides should improve the future vision for food systems. These improvements should be made by establishing a better link between the demand side and the supply side;

\section{Improvements regarding the supply side of models}

(e) In many models such as GTAP, Fapri or Globiom, food processing is not modelled, except for models that focus on specific products, such as dairy products. Consequently, demand and supply are poorly linked, since margins and contracts related to processors and retailers are neglected. It seems that even simplistic ways of modelling food processing may improve the situation. With the GTAP model, some attempts have been recently realised for developing new modules that integrate global value chains, but they are still nascent projects (Antimiani et al. 2018);

(f) One option could be to take advantage of more specific works on the food chain and/or food industry, in order to better characterise price formation along the food chain and evaluate how changes in the price of agricultural raw materials affect consumer prices. By using real purchase data, Bonnet and Bouamra-Mechemache (2016) estimate a structural econometric model of demand that takes into account the relationships between manufacturers and retailers with some assumptions regarding the bargaining power between different agents. Such a structural econometric model allows us to distinguish between processors and retailers' margins, which is promising for understanding vertical relationships. Different margins, as per those for conventional versus organic products, could be integrated into a calibrated model including agents from the supply chains;

(g) Some effort should be made to better consider sunk costs and investments arising from major shifts within the food system. For sectors with a declining demand, some assets will become obsolete, while sectors with a booming demand will require new investments. For instance, boosting the consumption of legumes such as lentils, beans and peas with a longer cycle of rotation in order to have a natural source of nitrogen in Western countries requires new investments at various stages of the chain (from investments in new silos to investments in promoting the products by retailers). Evaluating investments and their impacts on market functioning is difficult, as the monetary estimations of assets could be overvalued depending on the dynamic adjustments of the markets (Boland et al. 2014). It should be noted that vertical farms, urban farms, hydroponic systems, or high-tech farms are extremely capital intensive, a point that should be emphasised when new options for food security are studied; 
(h) The role of international trade towards a sustainable food diet should be carefully studied. On the one hand, international trade brings social benefits with a diversification of risks, possible reductions in food prices and imports of products that cannot be produced in some locations. International trade has considerably broadened the range of products available for consumers, and as such, significantly impacts our diet. On the other hand, international trade often leads to excessive crop specialization that may ruin soil fertility, biodiversity and/or "global commons", such as rainforests, in particular when environmental regulations are weak. The various impacts of environmental or safety regulations on trade are difficult to measure, because trade-offs in supply chains are particularly challenging to estimate. Recently, the issue of "food localism" (that is, purchasing locally-grown or produced food) has gained momentum. Indeed, preferences by some consumers for locally-grown food may impact both trades and diet, and is a topic deserving further study in the future;

(i) Regarding the optimal policy to improve diet, the important issues of both time evolution and transition have often been overlooked. In particular, the transition from the current agro-food sector model to a new model aligned with nutrition and low-carbon objectives requires a progressive shift in each stage of the supply chain. Such a shift will make some skills, practices and materials obsolete, which may mean that physical and human capital will need to be renewed. The situation of many farmers, particularly in the meat sector, is already difficult, and a transition, if poorly implemented, could further aggravate the situation. More attention is necessary to carefully take into account any transitions when policies are implemented.

\section{Improvements regarding the measures of inequality}

In introducing this important topic, it should be emphasised that we aim to consider more precise measures regarding variations in income, surpluses and welfare that arise from possible sustainable policies, which is an essential step for a rigorous analysis of inequality. Although inequality in the domain of food sustainability is linked to many topics, such as food accessibility, farmers' fragility or the share of added values between producers in the supply chain, we restrict our attention to a few issues related to consumption;

(j) A frequently overlooked dimension in the analysis of policies favouring more sustainable food system is the inequality dimension. This topic is particularly important in the case of food, as price increases are likely to have regressive effects, striking the "poor" consumers more than the wealthy ones. This is because poor consumers have fewer options available to them for substitutions to expensive alternatives, and they also devote a larger share of their income to food than richer consumers do. On the whole, promoting more sustainable food is likely to increase prices. For example, the reduction of pesticide application to improve both human and environmental health is likely to increase the price of agricultural products due to lower yields. Similarly, organic production also leads to higher prices for agricultural products. If taxes are designed to combat climate change, 
this will also increase prices. ${ }^{8}$ On the other hand, as mentioned above, a shift from animal products to plant-based products is likely to decrease food expenditure. Taking into account how these different elements (among others) differently affect consumers according to their income level is an important issue. One solution may involve estimating a specific demand for households divided by income quartiles or by developing quantile regressions focalizing on the income distribution. But more generally, unequal access to food implies political choices based on the preferences of citizens. The inequality indicator should be precise, and citizens' preferences could be studied in order to better understand how regulations could help poor consumers.

From our point of view, all ideas presented here suggest that it might be possible to integrate: first, a larger set of substitutions between foods products by consumers; and second, adjustments in the supply chains by considering sunk costs and margins incurred by farmers, processors and retailers, as explained above. By making a link with farmers' choices, such a model could integrate a land use module to also estimate the impact of dietary shifts on land price and land allocation. By making a link with consumption, the model could then also integrate an epidemiological model in order to better assess the impact of different dietary scenarios on diet-related diseases. We think that such a task is difficult to realise, as many data and a great deal of specific information would need to be collected but is technically possible. This task is a suggestion to ignite debate and to gather constructive criticism.

\section{Conclusion}

By complementing dietary models, economic approaches are useful and are required to outline the markets adjustments that are essential for understanding behaviours. However, improvements are necessary in order to gain relevance. We have underlined that new developments should integrate, in particular: first, possible substitutions between foods categories by consumers; second, adjustments in supply chains; and third, measures of inequality resulting from significant changes towards sustainability. Such a task is difficult to realise but technically possible. Such an effort is important in order to understand the social consequences of a transition towards sustainable food systems. The following articles in this special issue on the Economics and Sociology of the Food-Health-Environment Nexus are a "first step" towards an improved understanding of behaviours and market adjustments.

Although economic models are imperfect, they are useful in order to be frank in terms of trade-offs between the various objectives defining sustainability, the impacts of regulatory tools on markets adjustments, and agents' surpluses/benefits. Economic evaluations should be emphasised and taken into account in the political agendas of various international institutions, such as the FAO, WHO or the World Bank in making sustainable food systems acceptable for many agents.

\footnotetext{
${ }_{8}^{8}$ Remler (2004) underlines this regressivity effect for tobacco, and Allcott et al. (2019) discuss the case of soda taxes.
} 
Acknowledgements We thank the editor Ronan Le Velly and two anonymous reviewers for their comments. The authors only are responsible for any omissions or deficiencies.

Funding information This research has been financed by the project DIETPLUS, grant ANR17-CE210003 provided by the French National Agency for Research (ANR). It has also been financed by the ANR under the Investments for the Future (Investissements d'Avenir) program, grant ANR-17-EURE-0010.

\section{Compliance with ethical standards}

Conflict of interest The authors declare that they have no conflict of interest.

\section{References}

Agrimonde-Terra. (2018). Land use and food security in 2050: a narrow road. Edited by M. De Lattre-Gasquet and Olivier Mora. Quae editor, Paris.

Afshin, A., \& GBD 2017 Diet Collaborators. (2019). Health effects of dietary risks in 195 countries, 19902017: A systematic analysis for the Global Burden of Disease Study 2017. The Lancet, 393(10184), 1958-1972.

Allcott, H., Lockwood, B. B., \& Taubinsky, D. (2019). Should we tax sugar sweetened-beverages? An overview of theory and evidence. Journal of Economic Perspectives, 33(3), 202-227.

Antimiani, A., Fusacchia, I., \& Salvatici, L. (2018). GTAP-VA: an integrated tool for global value chain analysis. Journal of Global Economic Analysis, 3(2), 69-105.

Blezat Consulting, le Crédoc et Deloitte Développement Durable (2017). Étude prospective sur les comportements alimentaires de demain et élaboration d'un dispositif de suivi des principales tendances de consommation à destination des entreprises de la filière alimentaire. La France en 2025. Janvier 2017. Paris, France.

Boland, M. A., Crespi, J. M. and Turner, T. M. (2014). Measuring sunk costs in agricultural and food industry assets: Why some assets sell below appraisal. Journal of Agricultural \& Food Industrial Organization 12(1), 1-15.

Bonnet, C., \& Bouamra-Mechemache, Z. (2016). Organic label, bargaining power, and profit-sharing in the French fluid milk market. American Journal of Agricultural Economics, 98(1), 113-133.

Bonnet, C., Bouamra-Mechemache, Z., \& Corre, T. (2018). An environmental tax towards more sustainable food: empirical evidence of the consumption of animal products in France. Ecological Economics, 147, 48-61.

Brunelle, T., Coat, M., \& Viguié, V. (2017). Demand-side mitigation options of the agricultural sector: potential, barriers and ways forward. OCL, Oléagineux Corps gras Lipides, 24(1), D104.

Deaton, A., \& Muellbauer, J. (1980). Economics and consumer behavior. Cambridge University Press.

Disdier, A. C., \& Marette, S. (2012). Taxes, minimum-quality standards and/or product labeling to improve environmental quality and welfare: experiments can provide answers. Journal of Regulatory Economics, $41,337-357$.

FAO (2019) The State of Food Security and Nutrition in the World 2019. FAO, July 2019, Roma.

Fapri (Food and Agriculture Policy Research Institute) (2019) General information available at http://www. fapri.iastate.edu/used. Ames, IA, USA.

Globiom (Global model to assess competition for land use between agriculture, bioenergy, and forestry) (2019). General information available at http://www.globiom.org/. Vienna, Austria.

GTAP (2019). General trade analysis project. https://www.gtap.agecon.purdue.edu/ Purdue, USA.

Harguess, J.M., Crespo, N.C., \& Hong, M.Y. (2020). Strategies to reduce meat consumption: a systematic literature review of experimental studies. Appetite, 144, Article 104478.

Hartmann, C., \& Siegrist, M. (2017). Consumer perception and behaviour regarding sustainable protein consumption: a systematic review. Trends in Food Science \& Technology, 61, 11-25.

IPCC (2019). The Intergovernmental Panel on Climate Change) Climate Change and Land: an IPCC special report on climate change, desertification, land degradation, sustainable land management, food security, and greenhouse gas fluxes in terrestrial ecosystems at its 50th Session held on 2-7 August 2019.

Irz, X., Leroy, P., Réquillart, V., \& Soler, L. G. (2015). Economic assessment of nutritional recommendations. Journal of Health Economics, 39, 188-210. 
Jones, J. M., Garcia, C. G., \& Braun, H. J. (2019). Perspective: whole and refined grains and health - evidence supporting "make half your grains whole". Advances in Nutrition, 2019(00), 1-15. https://doi. org/10.1093/advances/nmz114.

Kahneman, D., \& Knetsch, J. (1992). Valuing public goods: the purchase of moral satisfaction. Journal of Environmental Economics and Management, 22, 57-70.

Kemper, J. A. (2020). Motivations, barriers, and strategies for meat reduction at different family lifecycle stages. Appetite, 150, 104644.

Krystallis, A., Grunert, K. G., de Barcellos, M. D., Perrea, T., \& Verbeke, W. (2012). Consumer attitudes towards sustainability aspects of food production: insights from three continents. Journal of Marketing Management, 28(3-4), 334-372.

Lakdawalla, D., Philipson, T., \& Bhattacharya, J. (2005). Welfare-enhancing technological change and the growth of obesity. American Economic Review, 95(2), 253-257.

Lock, K., Smith, R. D., Dangour, A. D., Keogh-Brown, M., Pigatto, G., Hawkes, C., Fisberg, R. M., \& Chalabi, Z. (2010). Health, agricultural, and economic effects of adoption of healthy diet recommendations. The Lancet, 376(9753), 1699-1709.

Lusk, J. L. (2014). Are you smart enough to know what to eat? A critique of behavioural economics as justification for regulation. European Review of Agricultural Economics, 41(3), 355-373.

Lusk, J. L., \& Shogren, J. F. (2007). Experimental auctions. Methods and applications in economic and marketing research. Cambridge: Cambridge University Press.

Marette, S., Roosen, J., \& Blanchemanche, S. (2008). Taxes and subsidies to change eating habits when information is not enough: an application to fish consumption. Journal of Regulatory Economics, 34, 119-143.

Masset, G., Vieux, F., Verger, E. O., Soler, L.-G., Touazi, D., \& Darmon, N. (2014). Reducing energy intake and energy density for a sustainable diet: a study based on self-selected diets in French adults. American Journal of Clinical Nutrition, 99, 1460-1469.

Meunier, G. (2019). Economic assessment of nutritional recommendations: a comment. Journal of Health Economics, 65, 43-47.

Milford, A. B., Le Mouël, C., Bodirsky, B. L., \& Rolinski, S. (2019). Drivers of meat consumption. Appetite, 141(2019), 104313.

NBER (2019). The economics of poverty traps. Editors: C. B. Barrett, M. Carter, J-P. Chavas. University of Chicago Press and National Bureau of Economic Research. Washington D.C., USA.

Poore, J., \& Nemecek, T. (2018). Reducing food's environmental impacts through producers and consumers. Science, 360, 987-992.

Ranganathan J., Vennard D., Waite, R., Lipinski, B., Searchinger, T., Dumas, P., Forslund, A., Guyomard H., Manceron S., Marajo-Petitzon E., Le Mouël C., Havlik P., Herrero M., Zhang X., Wirsenius S., Ramos F., Yan X., Phillips M. and Mungkung R. (2016). Shifting diets for a sustainable food future. Working paper, installment 11 of creating a sustainable food future. Washington, DC: World Resources Institute. Accessible at http://www.worldresourcesreport.org.

Remler, D. K. (2004). Poor smokers, poor quitters, and cigarette tax regressivity. American Journal of Public Health, 94, 225-229.

Roosen, J., \& Marette, S. (2011). Making the 'right' choice based on experiments: regulatory decisions for food and health. European Review of Agricultural Economics, 38(3), 361-381.

Sans, P., \& Combris, P. (2015). World meat consumption patterns: an overview of the last fifty years (19612011). Meat Science, 109, 106-111.

Searchinger, D., Wirsenius, S., Beringer, T., \& Dumas, P. (2018). Assessing the efficiency of changes in land use for mitigating climate change. Nature, 564, 249-254.

Springmann, M., Mason-D’Croz, D., Robinson, S., Wiebe, K., Godfray, H. C. J., Rayner, M., \& Scarborough, P. (2017). Mitigation potential and global health impacts from emissions pricing of food commodities. Nature Climate Change, 7, 69-74.

Springmann, M., Mason-D’Croz, D., Robinson, S., Wiebe, K., Godfray, H. C. J., Rayner, M., \& Scarborough, P. (2018). Health-motivated taxes on red and processed meat: a modelling study on optimal tax levels and associated health impacts. PlosOne, 13(11), 1-26.

Tavoularis G., \& Sauvage E. (2018). Les nouvelles générations transforment la consommation de viande. Credoc. Consommation et Mode de Vie, $\mathrm{n}^{\circ}$ 300. Paris, France.

Thaler R. (2015). Misbehaving. Norton. New York. USA.

Tilman, D., \& Clark, M. (2014). Global diets link environmental sustainability and human health. Nature, 515, $518-522$. 
Vieux, F., Darmon, N., Touazi, D., \& Soler, L. G. (2012). Greenhouse gas emissions of self-selected individual diets in France: changing the diet structure or consuming less? Ecological Economics, 75, 91-101.

Vieux, F., Perignon, M., Gazan, R., \& Darmon, N. (2018). Dietary changes needed to improve diet sustainability: are they similar across Europe? European Journal of Clinical Nutrition, 72(7), 951-960.

Whitmee, S., Haines, A., Beyrer, C., Boltz, F., Capon, A. G., Ferreira de Souza, B., Dias, A., Ezeh, A., Frumkin, H., Gong, P., Head, P., Horton, R., Mace, G. M., Marten, R., Myers, S. S., Nishtar, S., Osofsky, S. A., Pattanayak, S. K., Pongsiri, M. J., Romanelli, C., Soucat, A., Vega, J., \& Yach, D. (2015). Safeguarding human health in the Anthropocene epoch: report of the Rockefeller Foundation-Lancet Commission on planetary health. The Lancet, 386(10007), 1973-2028.

WHO. World Health Organization. (2009). Global health risks: mortality and burden of disease attributable to selected major risks, $70 \mathrm{pp}$. Geneva: Switzerland.

WHO. World Health Organization (2015). Q\&A on the carcinogenicity of the consumption of red meat and processed meat. Oct. 26, 2015, Geneva, Switzerland.

Willett, W., Rockström, J., Loken, B., Springmann, M., Lang, T., Vermeulen, S., Garnett, T., Tilman, D., DeClerck, F., Wood, A., Jonell, M., Clark, M., Gordon, L. J., Fanzo, J., Hawkes, C., Zurayk, R., Rivera, J. A., Vries, W. D., Sibanda, L. M., Afshin, A., Chaudhary, A., Herrero, M., Agustina, R., Branca, F., Lartey, A., Fan, S., Crona, B., Fox, E., Bignet, V., Troell, M., Lindahl, T., Singh, S., Cornell, S. E., Reddy, K. S., Narain, S., Nishtar, S., \& Murray, C. J. L. (2019). Food in the anthropocene: the eat-lancet commission on healthy diets from sustainable food systems. The Lancet, 393(10170), 447-492.

WWF. World Wildlife Fund (2018). Vers une Alimentation Bas Carbone, Saine et Abordable. October 2018, Paris France.

Publisher's note Springer Nature remains neutral with regard to jurisdictional claims in published maps and institutional affiliations. 